Post-print version. Pedro Lastra González, Miguel Ángel Calzada Pérez, Irune Indacoechea Vega, Daniel Castro Fresno, Ángel

Vega Zamanillo (2015). "Asphalt concrete mixture with recycled aggregates and modified bitumen at reduced

temperature". International Journal of Civil Structural Engineering. Volume 2, Issue 2, Pages 154-159. ISSN 2372-3971.

\title{
Asphalt concrete mixture with recycled aggregates and modified bitumen at reduced temperature
}

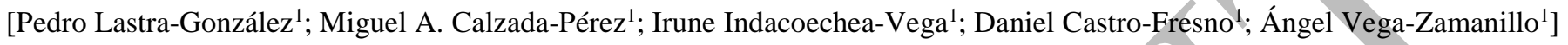

\begin{abstract}
The GREENROAD project was born to demonstrate a technically feasible alternative to conventional mixtures and to improve the sustainability of the road sector.

The project involves the development of Asphalt Concrete mixture manufactured with steel slag of Electric Arc Furnace, which is produced in the region and currently implies a high environmental cost; RAP from other mixtures; and bitumen modified with end-oflife tyres. Besides, a wax has been used to decrease the manufacture temperature and improve the environmental impact.
\end{abstract}

Finally, a mixture with more than $80 \%$ of recycled aggregates and with a decrease of temperature from $20^{\circ} \mathrm{K}$ to $30^{\circ} \mathrm{K}$ was achieved in laboratory, reaching the requirements for the maximum category of heavy traffic level (T00) of the Spanish specifications.

Keywords—asphalt concrete, slag, RAP, wax, modified bitumen

\section{Introduction}

This Asphalt Concrete mixture has been developed as part of the GREENROAD project, whose aim is to improve the sustainability of the road construction.

The consumption of natural aggregates is, after water, the greatest consumption of natural resources carried out by man with $11.000 \mathrm{~kg} /$ person-year (1). The OECD stated that typically $10.000 \mathrm{~m}^{3}$ of aggregates are needed for each kilometre of two-lane road constructed (2).

Therefore, the traditional construction of road infrastructures has a direct environmental impact; however, this also signifies that roads construction with alternative techniques and materials can be a useful tool to improve the sustainability of road infrastructures.

In this project, by-products as slags from Electric Arc Furnace (EAF) and waste as Recycled Asphalt Pavement (RAP) have been used to replace natural aggregates.

Besides, materials are the most expensive cost in a hot asphalt mixture (about 70\%), so any decrease in the aggregates cost means an important economic advantage (3). Different cost categories are shown in the Fig. 1.

\footnotetext{
1.Pedro Lastra-González; Miguel A. Calzada-Pérez; Irune Indacoechea-Vega; Daniel Castro-Fresno; Ángel Vega-Zamanillo. School of Civil Engineering, University of Cantabria

Spain

E-mail: pedro.lastragonzalez@unican.es
} 


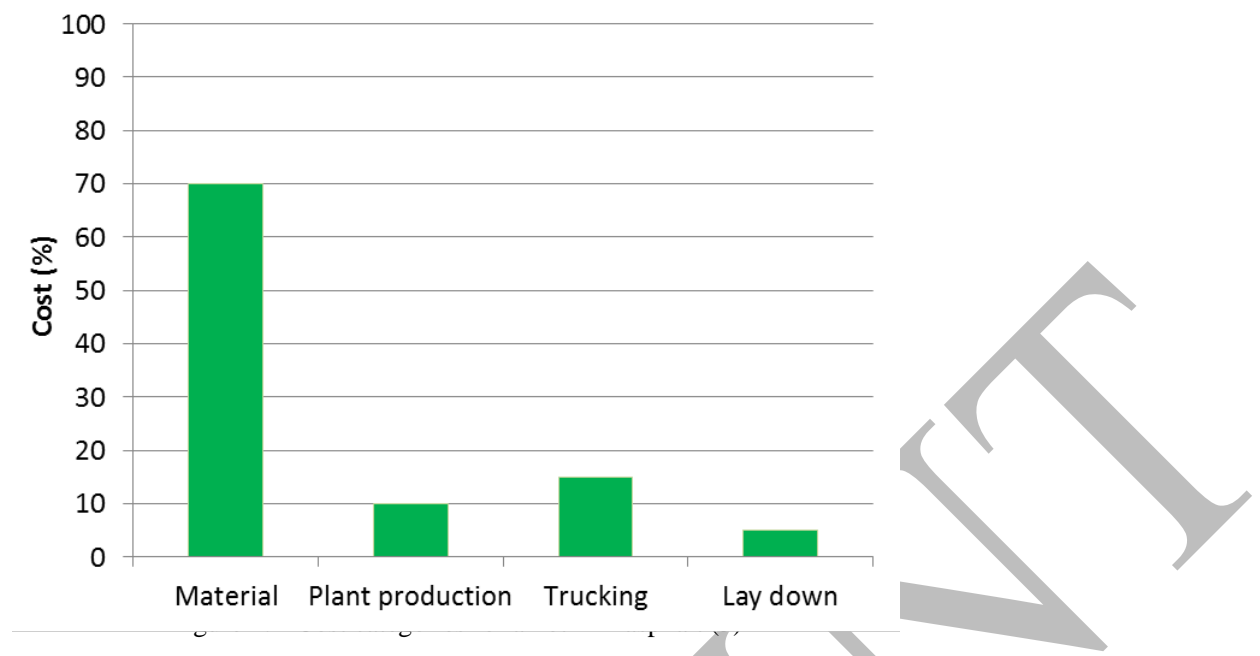

The bitumen modified with rubber is a good alternative to reuse part of the end-of-life tyres (which are considered as a resource by the directive on waste Directive 2008/98/EC, so they cannot go to landfills). Although it improves the bitumen mechanical performance, its viscosity penalizes its use because higher temperatures are required, increasing the pollution and the mixture cost.

This bitumen has been used in this project but modified with waxes, with the aim of reaching a good balance between its performance and its manufacturing temperature.

The EAF slag shows good properties for bituminous mixtures, especially as coarse aggregate, with a good Los Angeles coefficient and polish stone value. It has a good compatibility with the bitumen used in road pavements, and analysis has proven a good performance in stiffness, fatigue resistance and against plastic deformation $(4,5)$.

Some additional tests have to be carried out to analyse possible problems of lixiviate and expansiveness, which must be controlled (6).

The use of RAP has several economic and environmental advantages (7). It can be used in different ways, divided basically in relation to the RAP treatment: recycling in-place or in asphalt plant.

The percentage of RAP in the bituminous mixture depends on the type of mixture, the method to add it and its quality (aggregates and bitumen properties, and homogeneity). Although its use has been extended as a way to replace natural aggregate, it is forbidden or limited for surface layer or for some types of mixture in some countries $(7,8)$.

The asphalt industry is trying to produce in more efficient and sustainable ways. The use of waxes to decrease the manufacture and compaction temperature is one of the main options to reach this aim. The different types of mixture are shown in Table I depending on the temperature and the bitumen used (9).

The decrease of the manufacturing temperature when warm mix asphalt is produced replacing hot mix asphalt implies a significant reduction of gas emissions (10).

A project carried out with a Fischer-Tropsch (F-T) and synthetic amide wax (among other) concluded that the influence of the waxes is more significant under the melting temperature increasing the viscosity instead of above this temperature, decreasing it. The temperature decrease was not very significant (between $4.5^{\circ} \mathrm{K}$ and $10.7^{\circ} \mathrm{K}$ depending on the percentages and the wax type used). The viscosity of conventional bitumen with $3 \%$ and $6 \%$ of synthetic amide wax can be seen in Fig. 2 (11).

Other studies have analysed the performance of commercial additives with asphalt modified with rubber. The results have shown that the performance of the additives depends on the rubber contained. In case of F-T wax added to bitumen modified with rubber from $10 \%$ to $25 \%$, both the stiffness and resistance against plastic deformation are increased (12)

\section{Objectives}

This paper gathers the design of one Asphalt Concrete mixture with approximately 90\% of recycled material manufactured at reduced temperature with bitumen modified with crumb rubber from end-of-life tyres. The Spanish specifications divide the minimal required performance of the mixtures depending on the layer, climatic zone, and heavy traffic level (Table II).

The mixture has to fulfil the requirements per surface layer. As the climatic zone can be different for each road work, the objective was to reach the requirements for the highest heavy traffic level (T00) for any zone. 
TABLE I. CLASSIFICATION OF THE BITUMINOUS MIXTURES DEPENDING ON TEMPERATURE (9)

\begin{tabular}{|c|c|c|c|}
\hline $\begin{array}{l}\text { Bituminous } \\
\text { mixture }\end{array}$ & $\begin{array}{c}\text { Manufacturing } \\
\text { Temperature (K) }\end{array}$ & $\begin{array}{c}\text { Laying } \\
\text { Temperature (K) }\end{array}$ & Binder \\
\hline Hot mix & $420-450$ & $390-420$ & Bitumen \\
\hline Warm mix & $390-410$ & $370-390$ & $\begin{array}{r}\text { Bitumen + } \\
\text { Additives }\end{array}$ \\
\hline Low energy & 370 & $330-350$ & Bitumen \\
\hline $\begin{array}{l}\text { Half-Warm } \\
\text { mix }\end{array}$ & $310-370$ & $\begin{array}{c}\text { Ambient } \\
\text { Temperature }\end{array}$ & Emulsion \\
\hline Cold mix & $\begin{array}{c}\text { Ambient } \\
\text { Temperature }\end{array}$ & $\begin{array}{c}\text { Ambient } \\
\text { Temperature }\end{array}$ & Emulsion \\
\hline
\end{tabular}

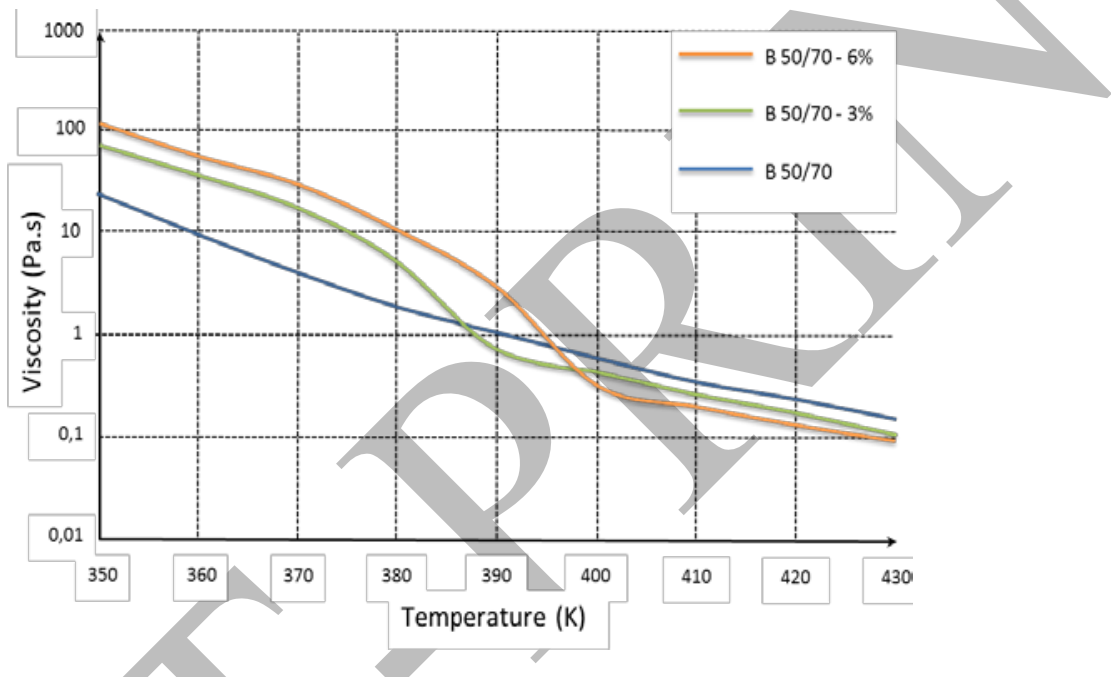

Figure 2. Viscosity of bitumen modified with synthetic amide wax (11)

\section{Method}

The process was divided in the dosage of recycled materials (EAF slag and RAP) in conventional conditions, and the analysis of viscosity with the waxes to modify the manufacture temperature.

\section{A. Analysis of viscosity}

A rotational viscometer was used to calculate the bitumen viscosities. First, the viscosity of the conventional bitumen with rubber was measured at different temperatures; the viscosity at manufacturing temperature (given by the supplier) was taken as reference. Afterwards, viscosities of the bitumen with additives were measured in the same conditions: the temperature that produced the same reference viscosity defined the theoretical decrease of temperature for each additive.

The objective was to select an additive that reduces the viscosity above the melting point, temperature under which it either increases the viscosity or keeps it.

TABLE II. DEMANDING PARAMETERS OF A BITUMINOUS MIXTURE

\begin{tabular}{|c|cccccccc|}
\hline Parameter & \multicolumn{3}{|c}{$\begin{array}{c}\text { low } \\
\text { performance }\end{array}$} & & & \multicolumn{1}{c}{$\begin{array}{c}\text { high } \\
\text { performance }\end{array}$} \\
\hline Layer & \multicolumn{2}{|c|}{ Base } & & Binder & & Surface \\
\hline $\begin{array}{c}\text { Traffic } \\
\text { level }\end{array}$ & T42 & T41 & T32 & T31 & T2 & T1 & T0 & T00 \\
\hline
\end{tabular}




\begin{tabular}{|c|ccc|}
\hline $\begin{array}{c}\text { Climatic } \\
\text { zone }\end{array}$ & Mild & Medium & Warm \\
\hline
\end{tabular}

\section{B. Dosage of GREENROADs mixtures}

The RAP was sieved by the maximum size aggregate of the mixture as only preparation; therefore, it included from filler size to maximum aggregate size. It was added as any aggregate in the same conditions, trying to simplify its use. The grading curve of its recovered aggregate was considered to dose the mixture.

The EAF slag completed the grading curve in the coarse fraction and the limestone did the same in the fine fraction. This dosage was carried out by volume due to the slags great density.

The tests required by the Spanish specifications were carried out with every dosage, the best was selected and the results defined the category of heavy traffic level in which the mixture can work.

After this step, all the tests were repeated in the same conditions but at reduced temperature incorporating the selected additive, to discover whether the mixture kept its performance.

\section{Material}

The mixture was designed with natural aggregate, slag from EAF and RAP, using as binder modified bitumen with rubber from end-of-life tyres (PMB 45/80-60 C).

The natural aggregate was limestone which was used only to complete the fine aggregates.

The slag used is the primary slag from the steel making process (black slag) from the Global Steel Company S.A. localized in Cantabria, Spain (Fig. 3).

It was tested as any aggregate to work in a bituminous mixture. Besides, the leaching (EN 12457-4) and expansiveness tests (EN 1744-1) were also performed. Fig. 4 presents its grading size.

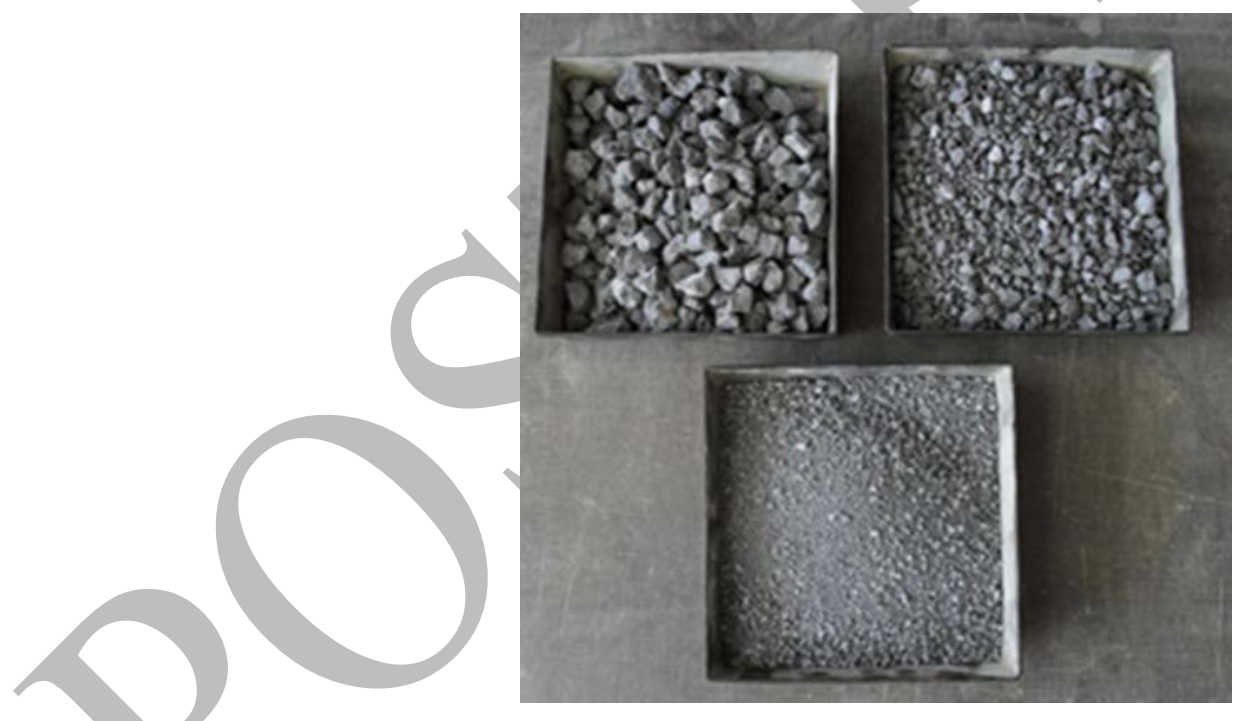

Figure 3. Black slag of EAF divided by size: 0/6; 6/12 and 12/18 


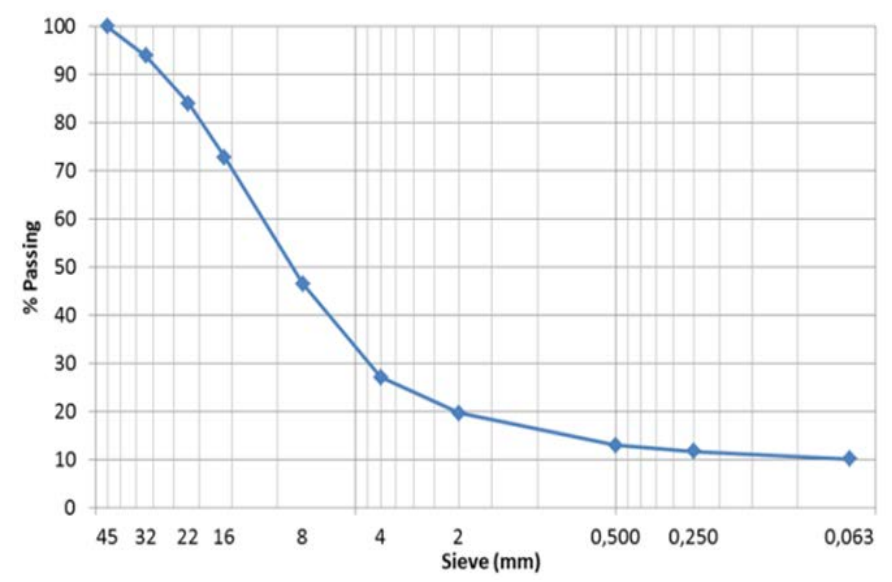

Figure 4. Slags grading size

RAP came from a milled pavement with approximately $4 \%$ of residual bitumen; its grading size and the grading size of the recovered aggregates when are separated of binder are presented in Fig. 5.
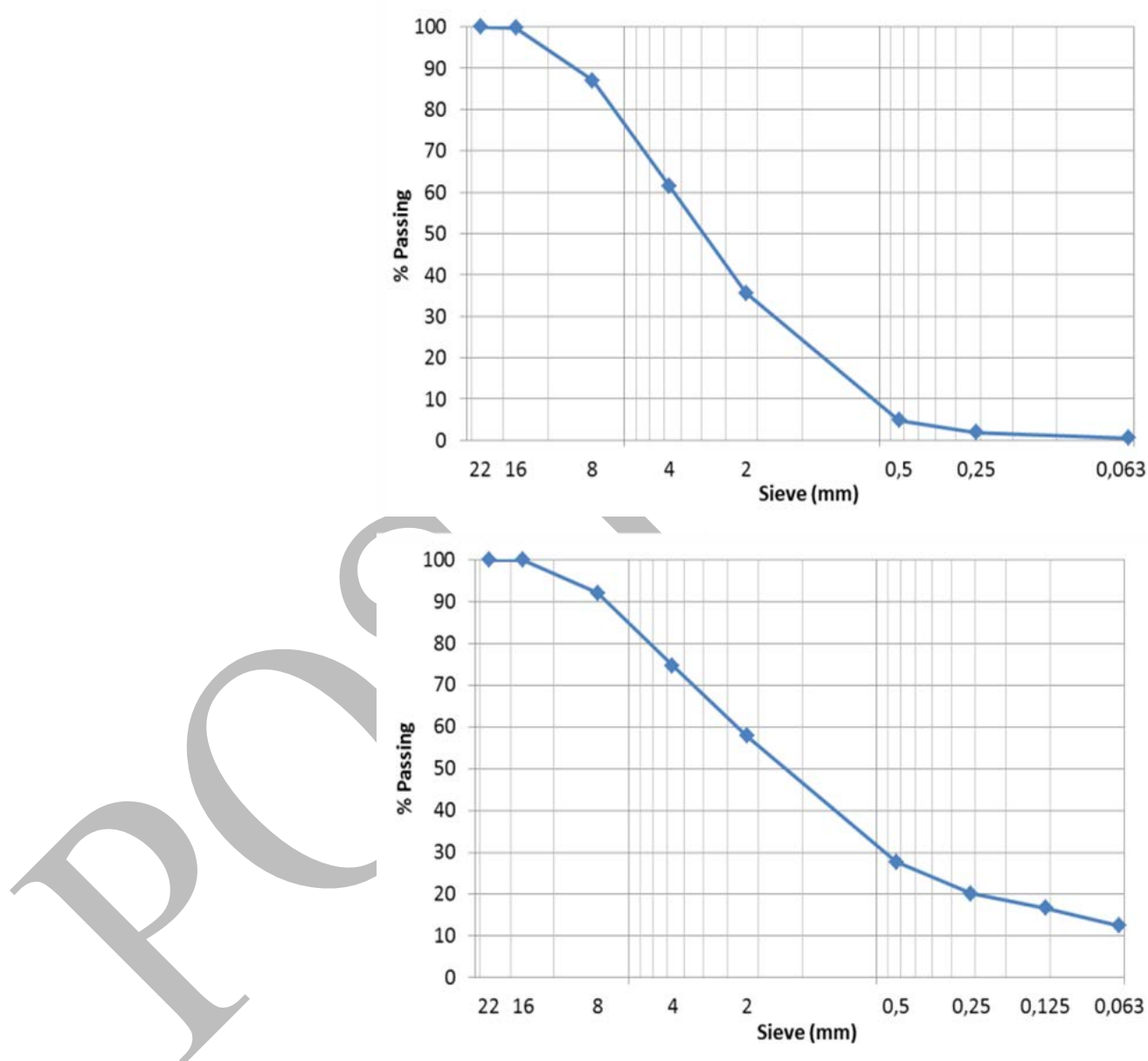

Figure 5. Grading size of RAP and recovered aggregates

The additives used were two types of waxes: a Fischer-Tropsch wax and fatty acid amide wax. They are shown in Fig. 6 and the characteristics are presented in the next table:

TABLE III. WAXES USED IN THE GREENROAD PROJECT 


\begin{tabular}{|c|c|c|c|}
\hline Type & $\begin{array}{c}\text { Melting temperature } \\
\text { (K) }\end{array}$ & $\mathbf{\%} /$ bitumen & Supplier \\
\hline Fischer-Tropsch & $375-390$ & 3 & SASOL \\
\hline Fatty acid amide & $415-420$ & 3 & UNDESA \\
\hline
\end{tabular}
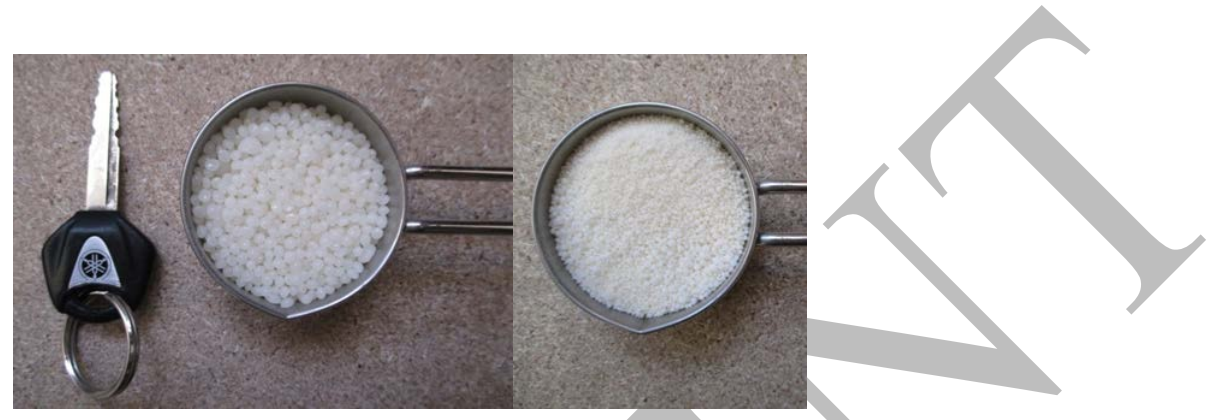

Figure 6. Fischer-Tropsch and Fatty acid amide wax

\section{v. Tests and results}

The results of the different mixtures are presented below.

\section{A. Analysis of viscosity}

The test was carried out with a Brookfield DV - I Prime viscometer (Fig. 7). The relative viscosity was measured from 353K to $463 \mathrm{~K}$. The additive was added to the bitumen with rubber in a proportion of $3 \%$ above bitumen. The mixture between the bitumen and additives was carried out at $423 \mathrm{~K}$. The results are shown in the Fig. 8.

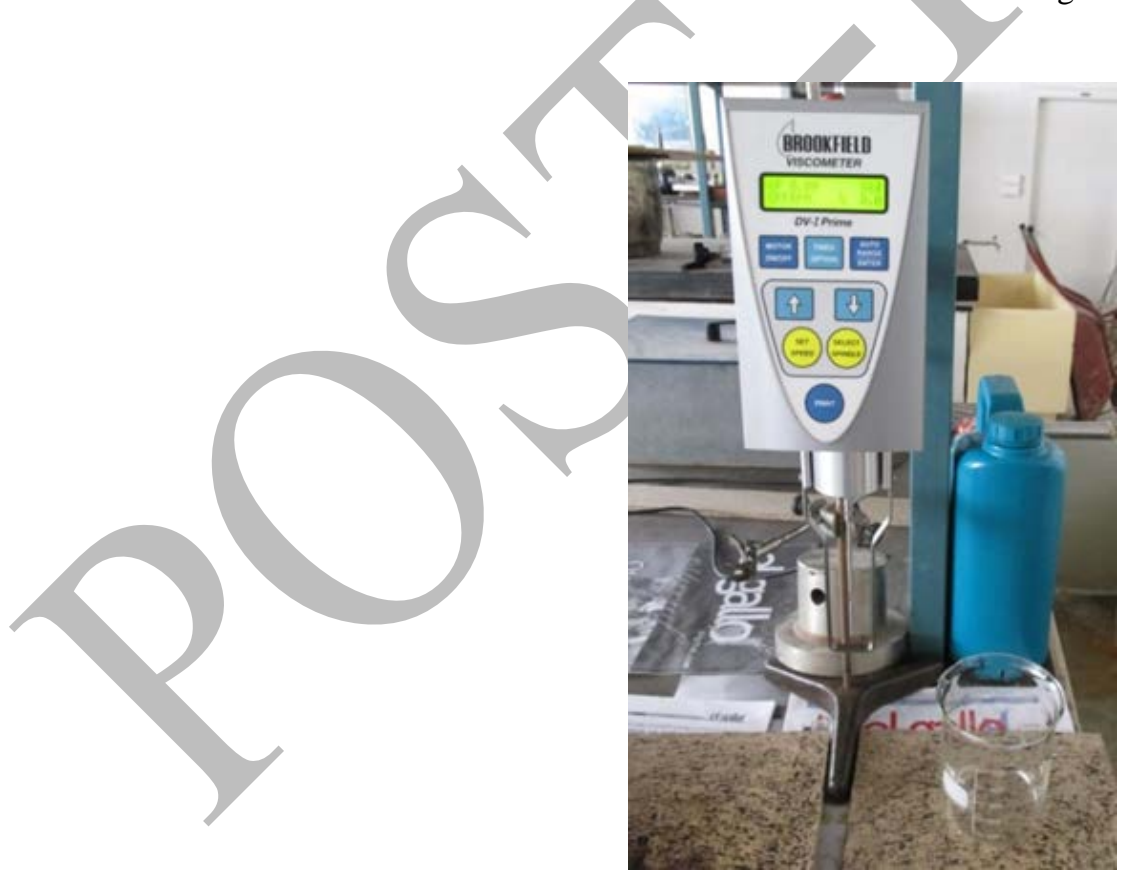

Figure 7. Brookfield viscometer 


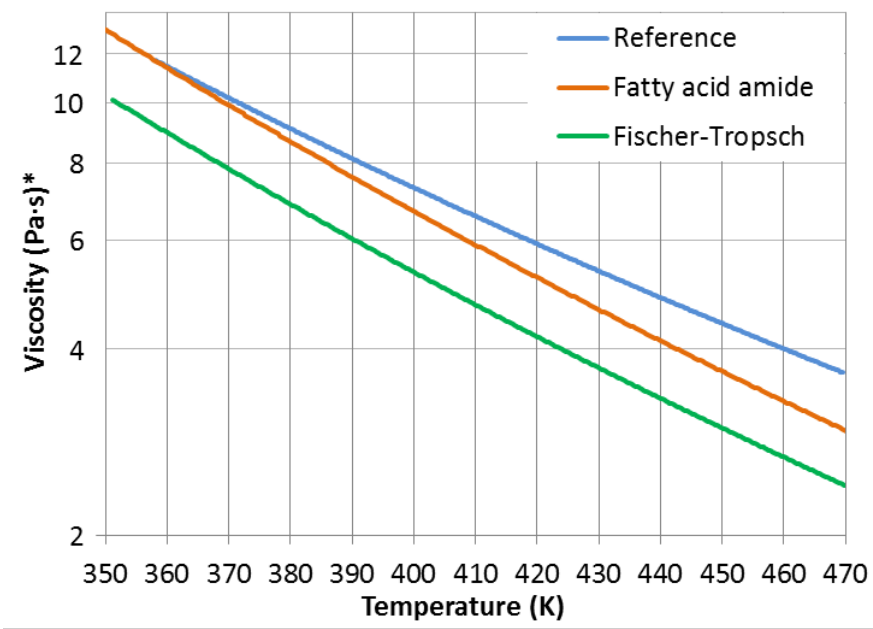

* This viscosity is relative to the bitumen with rubber, which is the reference.

Figure 8. Viscosity results

The fatty acid amide wax was selected because it recovers the viscosity earlier when the temperature decreases, so less risks of plastic deformation are assumed at ambient temperature.

With the manufacturing temperature recommended by supplier of reference bitumen (443K), we found that the reference viscosity is $4.8 \mathrm{~Pa} \cdot \mathrm{s}$. This viscosity was reached with the fatty acid amide wax at 425K, approximately. Therefore, in theory, when we add the fatty acid amide wax to the bitumen with rubber, it has the same viscosity at $425 \mathrm{~K}$ than this bitumen at $443 \mathrm{~K}$ in conventional conditions (Fig. 9).

\section{B. Dosage of Asphalt Concrete (AC 16 Surf S)}

The final design of the mixture was composed by $69 \%$ of slag, 14\% of RAP, 16\% of limestone and 1\% of added filler.

The mixture was manufactured initially at conventional temperature: $445 \mathrm{~K}$ the bitumen and $465 \mathrm{~K}$ the aggregates; when the fatty

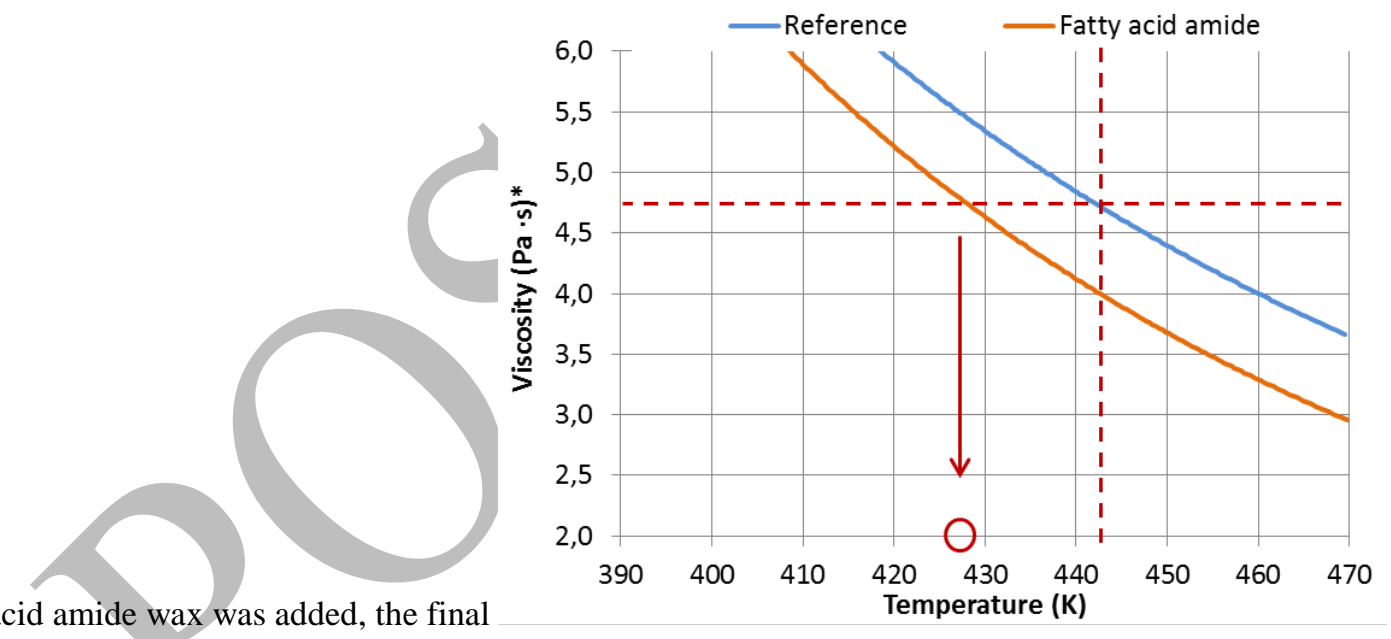

Figure 9. Reduced temperature

temperatures were $425 \mathrm{~K}$ for the bitumen and $435 \mathrm{~K}$ for the aggregates.

The results of the mechanical tests are presented below at conventional and reduced temperature. As reference the maximum and minimum values of Spanish specifications are also indicated.

- Voids test (EN 12697 - 8): the density and the voids in mixture and aggregates are shown in Fig. 10 and Fig. 11. The differences between mixtures are minimal. 


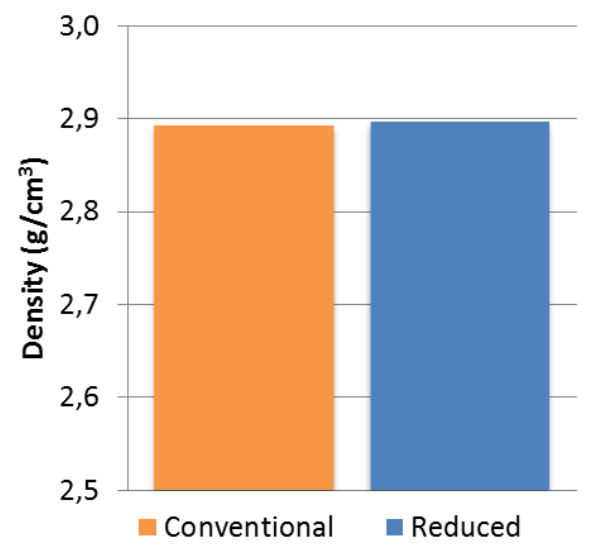

Figure 10. Density at conventional and reduced temperature
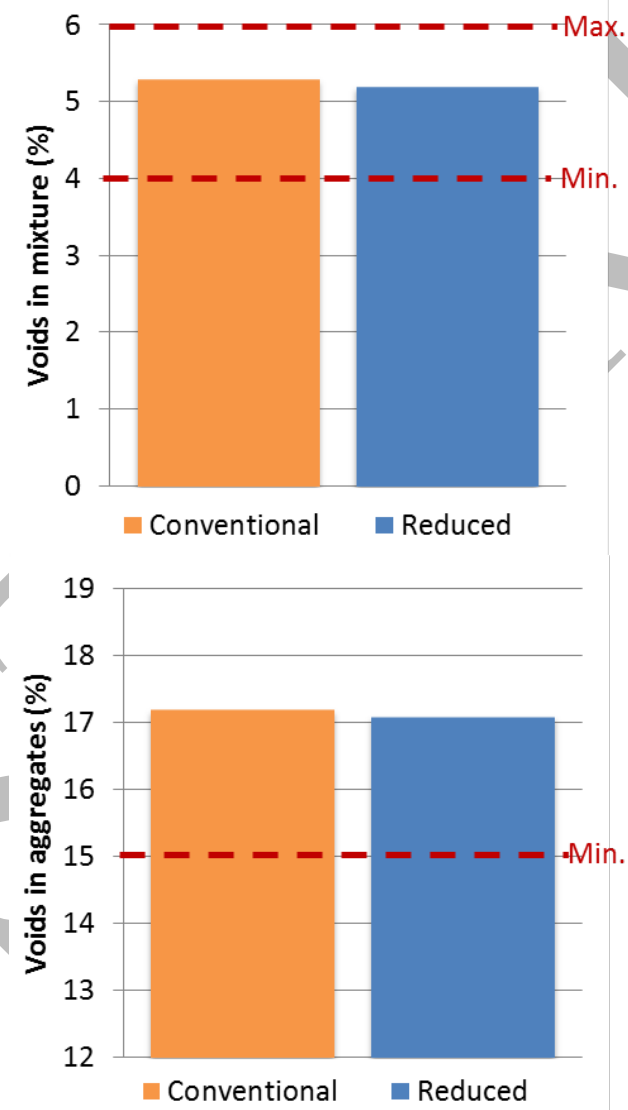

Figure 11. Voids at conventional and reduced temperature

- Water sensitivity test (EN 12697 - 12): The Indirect Tensile Strength Rate (ITSR) for both temperatures is shown in the Fig. 12. 


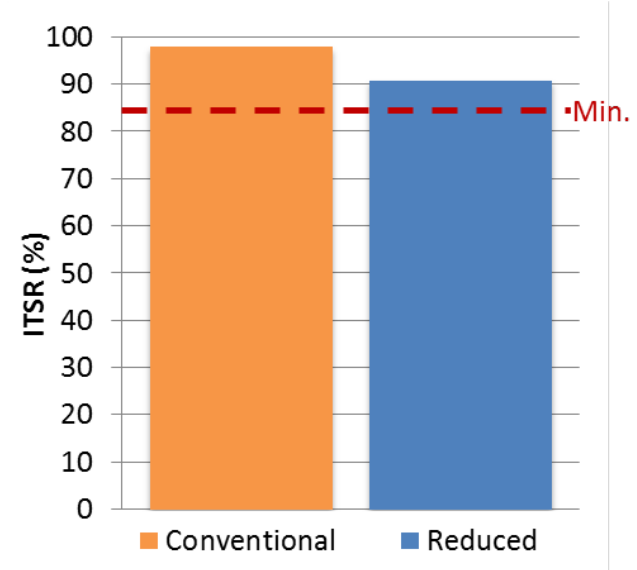

Figure 12. Water sensitivity results at conventional and reduced temperature

- Wheel tracking test (EN 12697 - 22): Fig. 13 shows the average slope (mm/1000 cycles) of wheel tracking deformation

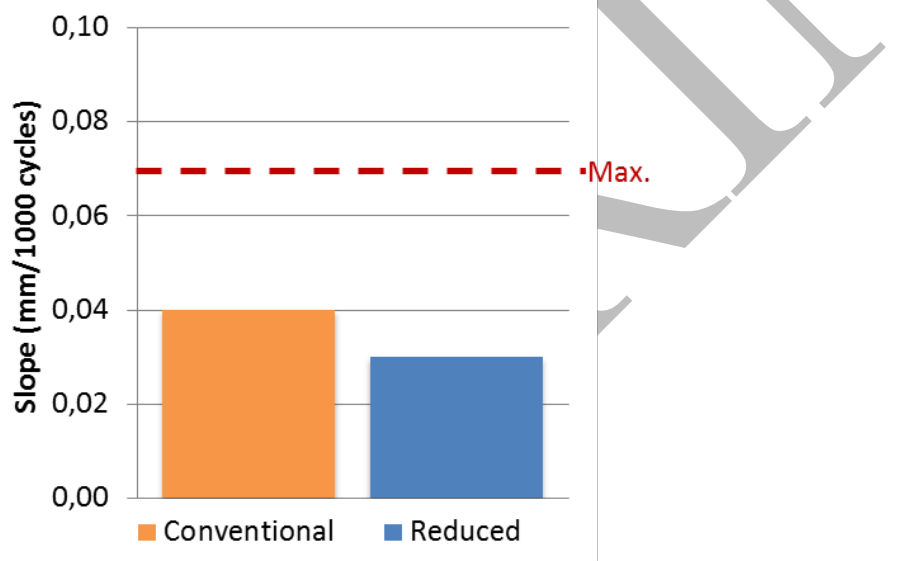

Figure 13. Wheel tracking test results at conventional and reduced temperature

All the results fulfil the requirements for the greatest traffic level in any climatic zone.

\section{Real stretch}

This mixture has been laid in a real stretch in Santander, Spain. The experimental stretch is an urban road in a touristic area. A conventional AC has been also laid to work as reference in the same road but in opposite direction of the GREENROAD mixture. Nowadays, monitoring works are being carried out. Below, images of the road are presented (Fig. 14 and Fig. 15).

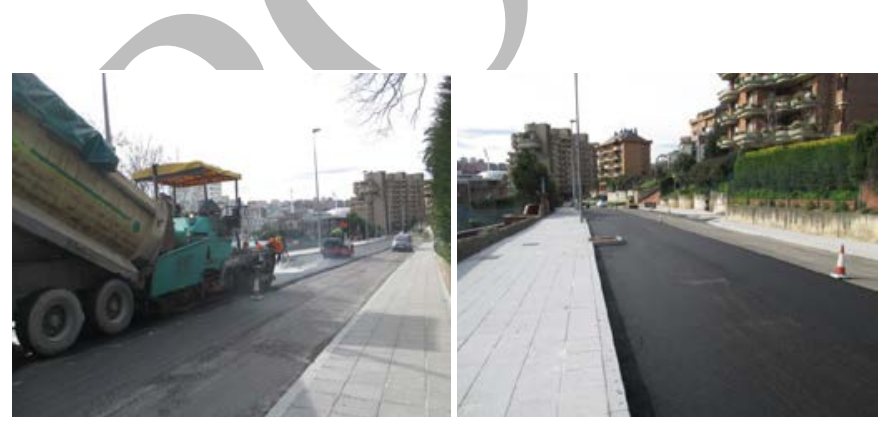

Figure 14. Road construction 

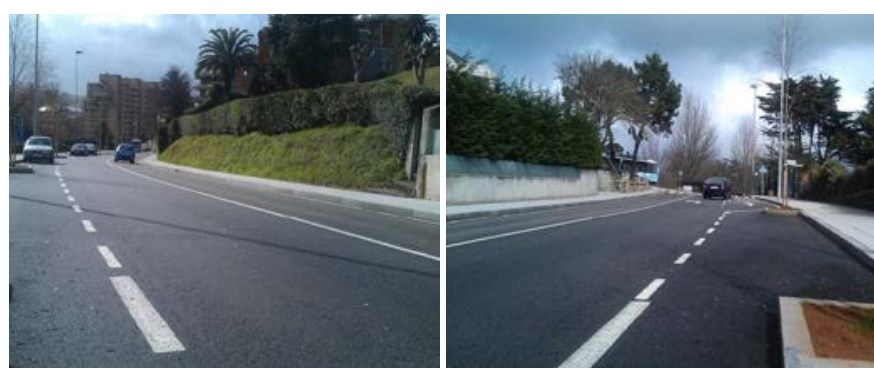

Figure 15. Road in use

\section{Conclusions}

Both GREENROAD mixtures use more than $80 \%$ of recycled aggregates, their performance was as good as conventional aggregates used for surface layer.

A decrease of temperature from $20 \mathrm{~K}$ to $30 \mathrm{~K}$ (including bitumen and aggregates) was achieved with the addition of wax.

Both mixtures, conventional and reduced, have fulfilled all the requirements for the highest heavy traffic level of Spanish specifications at laboratory level. Therefore, they could be used at any Spanish road if the scalability is correct. An experimental stretch is being performed to check this point.

Although the mandatory mechanical tests showed very similar results for both mixtures, the reduced mixture shows better performance against the plastic deformation and worse adherence in the water sensibility test.

The GREENROAD mixture with wax addition (reduced) needs less temperature to be manufactured than a mixture with conventional bitumen (50/70) at laboratory level.

\section{Acknowledgement}

GREENROAD is a project financed by the "LIFE+" program of the European Union. It has been performed by a consortium coordinated by COPSESA (Construcciones Obras Públicas San Emeterio S.A.) and integrated by GITECO (Construction Technology Applied Research Group, University of Cantabria), and Department of Public Works from the Santander City Hall.

\section{References}

[1] Luaces Frades C. La gestión de los recursos naturales de áridos. Problemática de abastecimiento en la comunidad de Madrid. I Congreso de Urbanismo y ordenación del territorio. "Ciudad y territorio". 200829 de Febrero de 2008:1-24.

[2] Organisation for Economic Co-operation and Development. Recycling strategies for road works. Road Transport Research Programme; 1997.

[3] Copeland A. Reclaimed Asphalt Pavement in Asphalt Mixtures: State of the Practice. 2011.

[4] Pasetto M, Baldo N. Mix design and performance analysis of asphalt concretes with electric arc furnace slag. Constr Build Mater. 2011;25(8):3458-68.

[5] Pasetto M, Baldo N. Performance comparative analysis of stone mastic asphalts with electric arc furnace steel slag: A laboratory evaluation. Materials and Structures/Materiaux et Constructions. 2012;45(3):411-24.

[6] Sorlini S, Sanzeni A, Rondi L. Reuse of steel slag in bituminous paving mixtures. J Hazard Mater. 2012;209-210:84-91.

[7] Van den Kerkhof E. In: Warm waste asphalt recycling in Belgium - 30 years of experience and full confidence in the future. 5th Eurasphalt \& Eurobitume Congress 2012; June 2012; Istanbul. Istanbul: ; 2012.

[8] Centro de estudios y experimentación de obras públicas (CEDEX). Reciclado de pavimentos asfálticos. España: ; 2012.

[9] Sánchez Alonso E. Efecto del tipo de aditivo en el comportamiento de mezclas bituminosas a diferentes temperaturas de fabricación y compactación [dissertation]. Spain: Universidad de Cantabria; 2012. 
[10] D'Angelo J, Harm E, Bartoszek J, Baumgardner G, Corrigan M, Cowsert W, et al. Warm-Mix Asphalt: European Practice. ; 2008.

[11] Giuliani F, Merusi F. Flow characteristics and viscosity functions in asphalt binders modified by wax. International Journal of Pavement Research and Technology. 2009;2(2):51-60.

[12] Wang H, Dang Z, You Z, Cao D. Effect of warm mixture asphalt (WMA) additives on high failure temperature properties for crumb rubber modified (CRM) binders. Constr Build Mater. 2012;35:281-8.

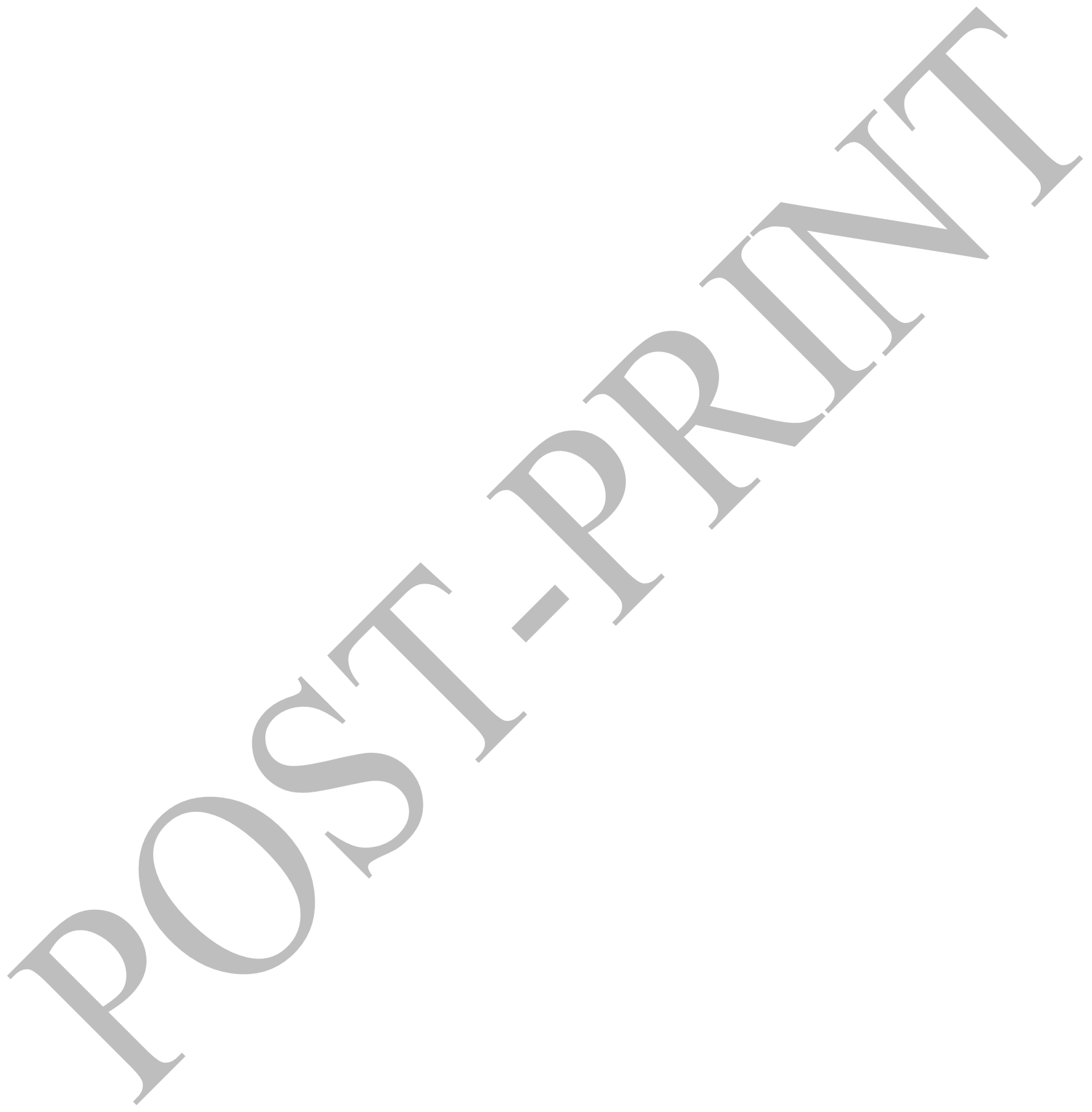

